\title{
Perception by Russian citizens of the Government of the Russian Federation D. A. Medvedev 2018-2020: political and psychological analysis
}

\author{
V. V. Vagina ${ }^{1}$
}

${ }^{1}$ Lomonosov Moscow State University, 27 building 4, Lomonosov Ave., Moscow 119991, Russian Federation

DOI: $10.18255 / 2412-6519-2020-3-218-229$

Research Article Full text in Russian

Currently, one of the relevant areas of political and psychological knowledge is the study of the content component of the images of power. The author in this article analyzes the image of the Government of the Russian Federation that has developed in the minds of Russian citizens. The image of power is the result of political perception, the formation of which is influenced by a combination of various factors: object, subjective, temporal, spatial, communicative.

The theoretical basis of the study is the theory of political perception. The process of political perception is complicated by the fact that the individual's attitude to power and its activity is formed not only as a result of access to the media, but also based on stereotypes inherent in the mass consciousness and based on the experience of the individual's interaction with the government.

The empirical basis was the data obtained as a result of a study aimed at studying the image of the Government of the Russian Federation in the minds of Russian citizens. The author of the article revealed some features of the perception of the Government of the Russian Federation by Russian citizens, for example, such as increasing the emotional level of perception and rejection of the current model of interaction in the "power-society" system, the need of citizens in a high-quality dialogue with a political institution.

The article analyzes in detail the visual component of the image of government, as well as the subjective and objective factors that determine the process of political perception.

The author comes to the conclusion that in the current realities of the political development of our country, there is some contradiction in the "power-society" system: even though confidence in power is declining, society is ready to compromise and dialogue.

Keywords: political perception; image of power; mass consciousness; factor model; political context; subjective factors; object factors; temporal factors

INFORMATION ABOUT THE AUTHORS

$$
\begin{array}{l|l}
\text { Vagina Vera V. } & \begin{array}{l}
\text { E-mail: vera.vladislavovna@mail.ru } \\
\text { Postgraduate student }
\end{array}
\end{array}
$$

For citation: Vagina V. V. Perception by Russian citizens of the Government of the Russian Federation D. A. Medvedev 2018-2020: political and psychological analysis // Social'nye i gumanitarnye znanija. 2020. Vol. 6, No 3. P. 218-229. (in Russ.)

(C) Vagina V. V., 2020

This is an open access article under the CC BY-NC-ND license (http://creativecommons.org/licenses/by-nc-nd/4.0/) 


\title{
Восприятие российскими гражданами Правительства РФ Д. А. Медведева 2018-2020 гг.: политико-психологический анализ
}

\author{
В. В. Вагина ${ }^{1}$
}

\author{
${ }^{1}$ Московский государственный университет им. М.В. Ломоносова, Ломоносовский просп., 27, корп. 4, \\ Москва, 119991, Российская Федерация \\ DOI: $10.18255 / 2412-6519-2020-3-218-229$ \\ УдК $323.2 ; 32.019 .52$ \\ Научная статья \\ Полный текст на русском языке
}

В настоящее время одним из актуальных направлений политико-психологического знания является изучение содержательного компонента образов власти. Автором в данной статье анализируется образ Правительства РФ, сложившийся в сознании российских граждан. Образ власти является результатом политического восприятия, на процесс формирования которого оказывает влияние совокупность различных факторов: объектных, субъектных, темпоральных, пространственных, коммуникативных. Теоретической базой исследования является теория политического восприятия. Процесс политического восприятия осложняется тем, что отношение индивида к власти и ее деятельности формируется не только в результате обращения к СМИ, но и исходя из стереотипов, присущих массовому сознанию, с опорой на опыт взаимодействия самого индивида с властью.

Эмпирическим основанием послужили данные, полученные в результате проведения исследования, направленного на изучение образа Правительства РФ в сознании российских граждан. Автором статьи были выявлены некоторые особенности восприятия Правительства РФ российскими гражданами, например, такие как повышение эмоционального уровня восприятия и непринятие текущей модели взаимодействия в системе «власть-общество», потребность граждан в качественном диалоге с политическим институтом.

В статье подробно проанализирован визуальный компонент образа правительства, а также субъектные и объектные факторы, обусловливающие процесс политического восприятия.

Автор приходит к выводу, что в текущих реалиях политического развития нашей страны наблюдается некоторое противоречие в системе «власть-общество»: даже несмотря на то, что доверие к власти снижается, общество готово идти на компромисс и диалог.

Ключевые слова: политическое восприятие; образ власти; массовое сознание; факторная модель; политический контекст; субъектные факторы; объектные факторы; темпоральные факторы

\section{ИНФОРМАЦИЯ ОБ АВТОРАХ}

$$
\begin{array}{l|l}
\text { Вагина Вера Владиславовна } & \begin{array}{l}
\text { E-mail: vera.vladislavovna@mail.ru } \\
\text { Аспирант кафедры социологии и психолог политики }
\end{array}
\end{array}
$$

Для цитирования: Вагина В. В. Восприятие российскими гражданами Правительства РФ Д. А. Медведева 2018-2020 гг.: политико-психологический анализ // Социальные и гуманитарные знания. 2020. Том 6, № 3. С. $218-229$. 


\section{Введение}

В современных условиях наблюдается возрастающий интерес к области социально-политических исследований в России. Данная тенденция обусловлена прежде всего тем, что за последние несколько лет в нашей стране произошли существенные изменения в политической сфере, оказавшие влияние на процесс восприятия обществом властных институтов и модель политического участия граждан. Факторный анализ политического восприятия позволяет расширить понимание о власти как таковой, получить новые знания о политическом процессе в России. Образ политических институтов, сформированный в массовом сознании, оказывает существенное влияние на установление и поддержание доверительных отношений в системе «власть-общество» [1]. В результате событий последних нескольких лет мы наблюдаем существенное снижение уровня доверия со стороны российских граждан ко всем политическим институтам в нашей стране, в частности к Правительству РФ, что и фиксируют крупные социологические центры ВЦИОМ [2] и Левада-Центр [3]. Говоря о причинах, оказавших влияние на данный процесс, нельзя обойти стороной актуальный политический и событийный контекст. Следует отметить, что непопулярные реформы, инициированные Правительством РФ в прошлом году и в начале текущего, оказали влияние на представления граждан о данном органе государственной власти.

\section{Теоретические основания исследования}

В качестве теоретической основы для исследования образов властных институтов в рамках политико-психологического подхода является теория политического восприятия. Политическим восприятием называется процесс, в результате которого происходит отражение в массовом и индивидуальном сознании как отдельных политических объектов (например, политических институтов), так и политической реальности в целом [4].

Важным для данной статьи при рассмотрении образа федерального Правительства является интерпретация таких понятий, как «имидж» и «образ». Отметим, что в англоязычной научной литературе данные понятия употребляются в качестве синонимичных, однако в отечественной научной мысли существуют различные подходы к их соотношению. Мы, основываясь на подходах Д. А. Леонтьева [5] и Е. Б. Шестопал [6; 7], будем рассматривать данные категории в качестве самостоятельных и не тождественных друг другу. Под политическим образом мы будем понимать отражение политических объектов в индивидуальном и массовом сознании, формирующееся естественным путем, тогда, как под имиджем - конструируемое целенаправленно.

Одним из важнейших понятий в области политико-психологических исследований является понятие «образ власти», который формируется в результате восприятия (перцепции) гражданами политических процессов [8].

Принято считать, что политическое восприятие является частным случаем социального восприятия [9]. Однако можно выделить ряд специфических черт, характерных исключительно для политической перцепции. Одним из ключевых отличий политического восприятия является то, что его результат не только отражает реальные характеристики политического объекта, но и находится под влиянием сложившихся в массовом сознании стереотипов, ценностей и установок, а сам процесс направлен в большей степени на отражение оценочных интерпретаций власти [10]. 
Рассмотрим специфические характеристики, которыми обладает процесс политического восприятия:

1. В большей степени отражает оценочные интерпретации в отношении политических объектов, чем отражает объективную реальность.

2. Политическое восприятие обладает некоторой двойственностью: на данный процесс оказывают влияние как внутренние факторы, связанные с субъектом восприятия, например, ценности, стереотипы и установки, присущие массовому сознанию, так и внешние факторы - политические, экономические, социальные и другие.

3. Чаще бывает опосредованным, чем непосредственным и происходит, например, через СМИ.

4. Характеризуется высокой слитностью эмоциональных и когнитивных элементов перцепции.

Комплексный анализ влияния внешних по отношению к индивиду и внутренних факторов позволяет сделать модель политического восприятия, разработанная профессором Е. Б. Шестопал и сотрудниками кафедры социологии и психологии политики факультета политологии МГУ им. М. В. Ломоносова. Данная модель опирается на несколько групп факторов, оказывающих влияние на результат процесса восприятия: объектные, субъектные, пространственные, темпоральные и коммуникативные [11].

Рассмотрим подробнее, на чем делается акцент при изучении факторов, обусловливающих процесс политического восприятия. Анализ объектных факторов включает в себя рассмотрение актуального политического контекста и особенностей самого объекта. Субъектный фактор касается социально-демографических и психологических характеристик граждан [12]. Анализ коммуникативного фактора осуществляется с точки зрения информационного обмена политической информацией между акторами и выбора коммуникационного канала [13]. При рассмотрении влияния темпорального и пространственного фактора на процесс политического восприятия исследователи отмечают, что принадлежность к определенной территории и время являются важными факторами, оказывающими влияние на трансформацию имеющихся политических образов [14].

Применительно к целям данной статьи для анализа образа Правительства РФ далее мы рассмотрим подробнее объектный и субъектный факторы.

Политическое восприятие - это сложный процесс, на который оказывает влияние большое количество факторов. При этом важно отметить, что формирование политического образа происходит в сознании индивида на двух уровнях - рациональном (осознанном) и иррациональном (бессознательном). Отличием является то, что на бессознательном уровне ведущая роль отводится эмоциональным элементам, слабо осознаваемым индивидом.

Анализ аффективных (эмоциональных) структур политического образа важен при изучении процесса восприятия, поскольку оказывает влияние и на когнитивные процессы индивида. Исследованиями подтверждено, что граждане могут испытывать сильные и яркие эмоции к политическим объектам даже в условиях «информационного голода» в отношении результатов их деятельности [15]. Проанализировать сложившийся политический образ на бессознательном уровне можно, опираясь на визуальные представления индивида о данном политическом объекте.

В рамках данной статьи мы сделаем акцент на изучении визуальных представлений российских граждан относительно Правительства РФ. 


\section{Методы}

Объектом исследования в данной статье является образ Правительства РФ в сознании российских граждан. Интерес также представляют особенности и ключевые тенденции в восприятии данного органа власти.

Эмпирической базой послужили данные, собранные в рамках исследования «Образ Правительства РФ в сознании российских граждан», полученные в 20182020 гг. Исследование носило качественный характер и проводилось с применением следующих методов: глубинного интервью с использованием проективной методики «Рисунок Правительства РФ» и неоконченных предложений. Данная методика позволяет проанализировать неосознаваемые уровни политических образов и сделать более глубокие выводы [16].

Выбор методов был обоснован характеристиками изучаемого объекта. Проективный тест позволяет проанализировать визуальный образ, сложившийся в массовом или индивидуальном сознании на бессознательном уровне. При анализе результатов проективного теста оценивается вся совокупность факторов: когнитивная, эмоциональная и поведенческая составляющие, мотивационный и смысловой компоненты [17].

Важно отметить, что интервью носило полустандартизированный характер и состояло из нескольких типов вопросов: закрытые, открытые, ассоциативные. По ходу проведения беседы респондентам задавались уточняющие вопросы с целью более объективной фиксации результатов. Анализ и интерпретация результатов, полученных в результате интервью, не предполагают количественной обработки.

Всего автором было проанализировано 350 интервью и рисунков. Следует отметить, что объём выборки соответствует требованиям, предъявляемым для качественных исследований. Несмотря на то, что выборка не является репрезентативной для страны в целом, она сбалансирована по полу и возрасту, а также региональному признаку. В исследовании приняли участие респонденты из нескольких регионов РФ, входящие в состав следующих федеральных округов: Центрального, Приволжского, Уральского и Северо-Кавказского. Для того чтобы оценить степень влияния социально-демографического фактора, респонденты были разделены на несколько возрастных групп: 18-25, 26-30, 31-40, 41-50, 51-60, 61-70 и старше 70 лет.

\section{Результаты исследования}

На протяжении последних нескольких лет политическая повестка неоднократно менялась, происходили ключевые изменения не только во внешней, но и во внутренней политике. Представляется очевидным, что события, протекающие в политическом поле, повлияли на представления граждан как о действующем федеральном правительстве, так и о власти в целом.

Российские социологические центры неоднократно фиксировали противоречивое отношение общественности к действовавшему в период 2018-2020 гг. Правительству РФ. Так, по данным ФОМ на 01.06.2018 года, более $45 \%$ россиян считали, что министры в составе действующего правительства профессиональные и компетентные [18], тогда как уже по данным Левада-Центр на 14.01.2019 года более 50 \% россиян отметили, что готовы отправить действующее правительство в отставку в полном составе [19].

Как отмечалось ранее, при анализе образа власти важно учитывать всю совокупность факторов. Безусловно, что на подобный контраст во мнении россиян оказал 
влияние событийный контекст, а именно непопулярные реформы, которые были реализованы Правительством РФ. В 2018-2020 гг. многие исследовательские центры фиксировали повышение общего эмоционального фона в восприятии властных институтов. Результаты исследования, полученные автором, подтверждают данный тезис.

Подобная оценка Правительства РФ как не оправдавшего возложенные на него надежды фиксируется и в ответах респондентов проведенного автором исследования. Отвечая на вопрос о достоинствах и недостатках в работе данного органа государственной власти, граждане отмечали «низкую эффективность, плохую освещенность проводимых реформ, отсутствие взаимодействия с представителями гражданского общества», «некомпетентность членов правительства», «жизнь обычных граждан не становится лучше», «а что сделано для простых людей? Оценка 3 принимая решения, думают о себе, а не о народе», «недостатков много, где основные это продвижение своих интересов, правительство не слышит народ и действует в интересах верхов, несправедливо завышенные ЗП, но при этом большая коррумпированность» и т. д.

Визуальный компонент образа власти исследовался с помощью проективной методики «Рисунок Правительства РФ».

Проанализировав рисунки респондентов, иллюстрирующие образ Правительства РФ в сознании россиян, можно заключить, что в большинстве своем они негативно окрашены и отражают существенные противоречия во взаимодействии между властным институтом и обществом. Например, по мнению многих респондентов, правительство - это своего рода закрытая структура, которую слабо интересует то, что происходит за её пределами. Например, один из респондентов отмечает следующее: «Настроение у меня сейчас к ним не позитивное, поэтому я вижу Правительство РФ как закрытую коробку на вершине горы, оторванную от настоящего мира и проблем» (см. рис. 1).

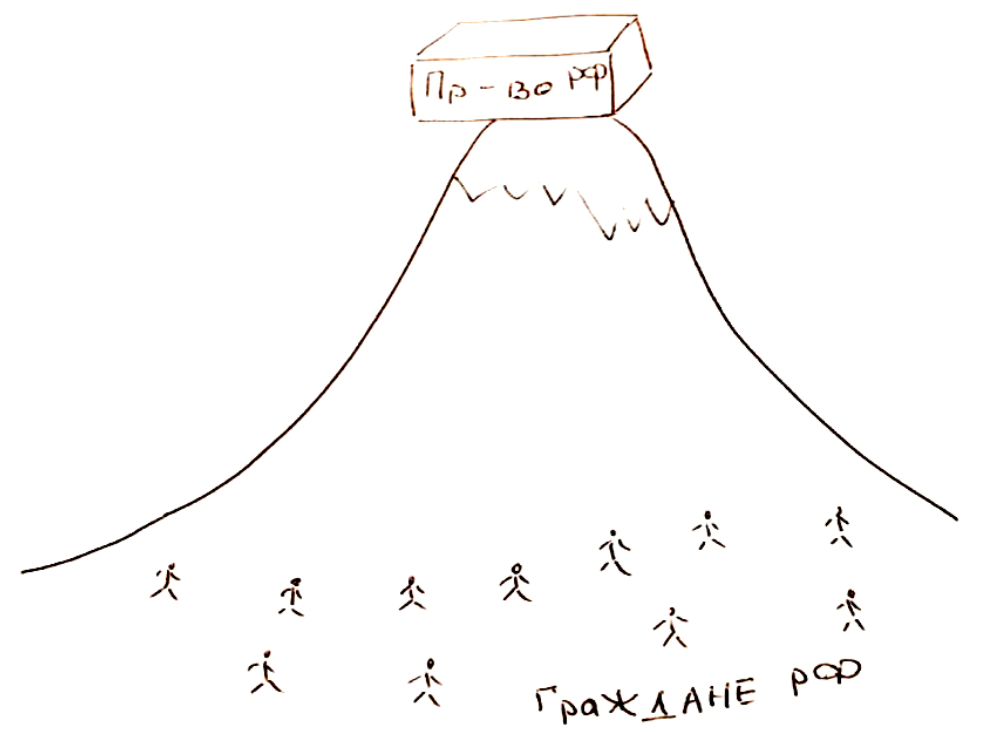

Рисунок 1. Образ Правительства РФ. Коробка на горе. 
Часто в рисунках фигурирует отражение некоторой оторванности членов правительства от реального мира и насущных проблем населения. Респонденты отмечают, что между властным институтом и обществом образовалась некоторая пропасть: «Я считаю, то они слишком далеко от народа. Они уже забыли, как живут обычные люди. Это два разных мира» (см. рис. 2).

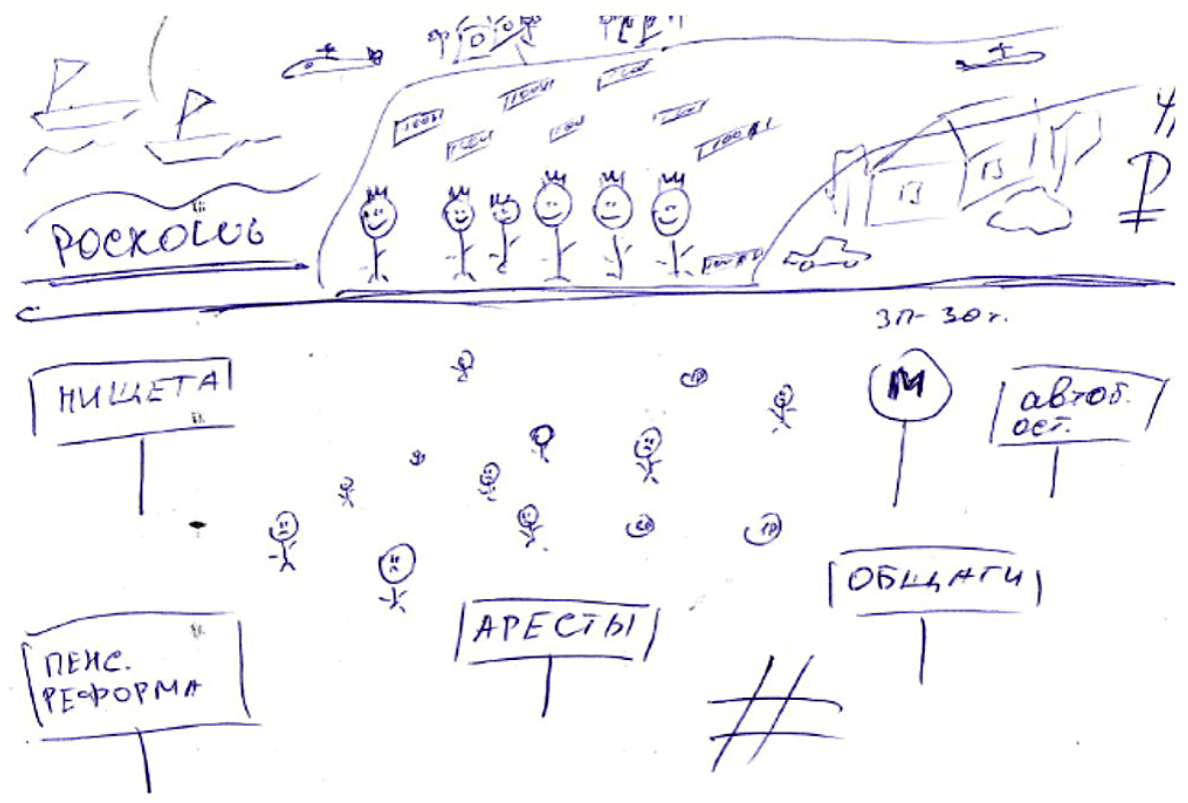

Рисунок 2. Образ Правительства РФ. Два разных мира.

Данная тенденция отражается респондентами и в ответах на вопросы интервью. Размышляя о том, каким должно быть Правительство РФ, чтобы жизнь в нашей стране изменилась в лучшую сторону, подавляющее большинство отмечало, что ждет от данного органа власти открытости по отношению к населению, честности, справедливости, компетентности и решений во благо народа: «честным», «работающим на благо народа», «внимательным к гражданам своей страны», «думать о людях, принимая решения», «более открытым, приближенным к нуждам людей, уделять больше внимания внутренним проблемам и туризму», «честным, открытым, отказаться от коррупции, прислушиваться к народу», «открытое кдискуссии, прозрачная структура, диалог с населением и малым и средним бизнесом» и т. д.

Важная тенденция, которая прослеживается в ответах респондентов, касается того, что Правительство РФ воспринимается с позиции пассивности и слабости: «Болото в лесу, где полная тишина и изредка сверчки издают звуки. Всё в тёмно-серых и тёмно-зелёных тонах» (см. рис. 3) или олицетворение Правительства через фигуру министра, который сидит за столом «сложа руки» (см. рис. 4). 


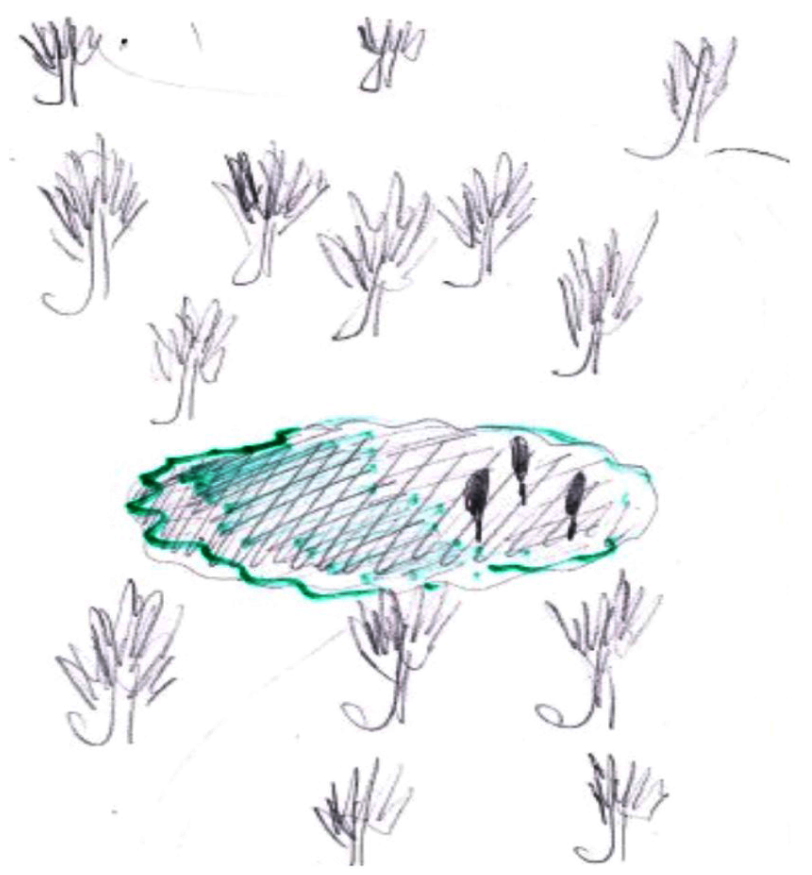

Рисунок 3. Образ Правительства РФ. Болото в лесу.

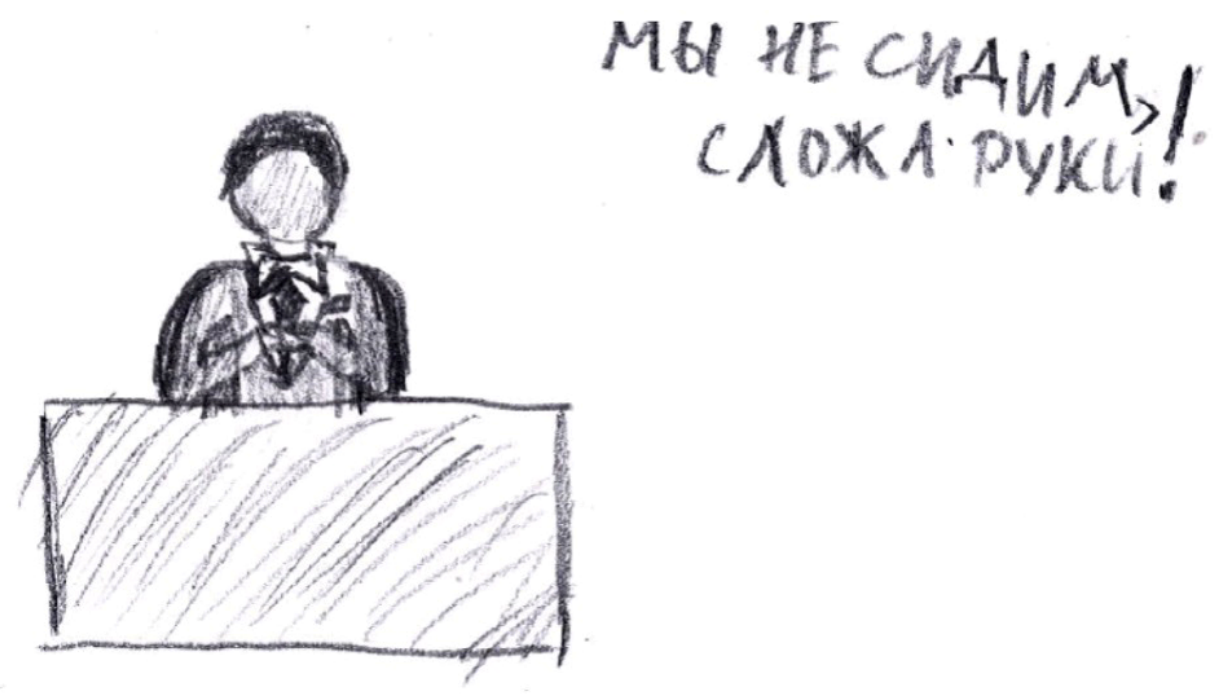

Рисунок 4. Образ Правительства РФ. Мы не сидим сложа руки. 
Многие респонденты отмечают, что Правительство РФ - это орган власти, который может влиять на состояние дел в стране, однако представления граждан о необходимых действиях со стороны данного властного института различаются с представлениями самого политического института. По мнению россиян, Правительство РФ находится где-то за высоким забором, управляет издалека и не решает актуальных проблем. Например, один из респондентов представляет данный орган власти в качестве пульта с рычагами, управляющими страной (см. рис. 5).

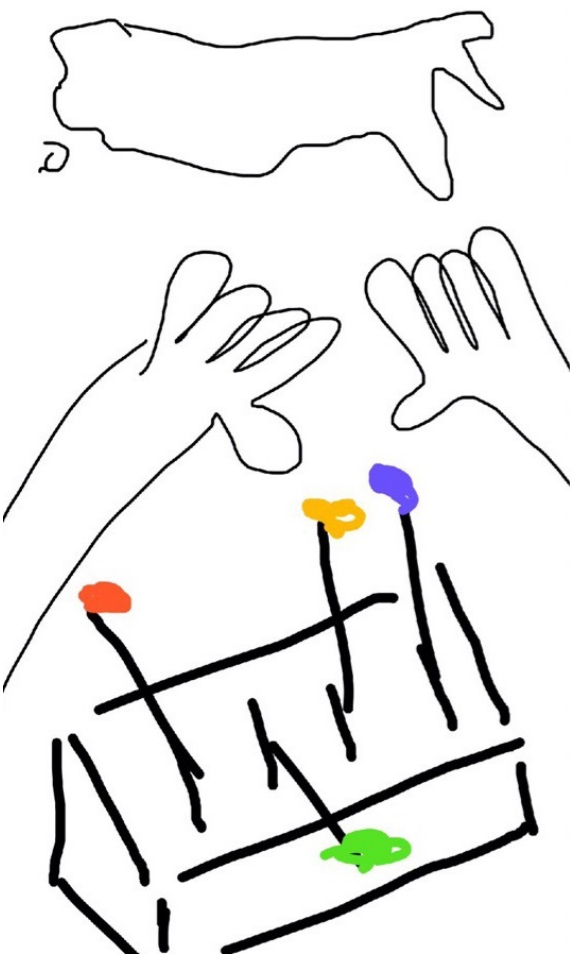

Рисунок 5. Образ Правительства РФ. Рычаги управления страной.

В процессе проведения глубинного интервью респондентам также задавался вопрос о том, что такое Правительство РФ. Данный вопрос задавался в формате неоконченного предложенного: «Правительство РФ - это...». Важно подчеркнуть, что большая часть ответов касалась формального статуса данного политического института: «высший исполнительный орган власти», «исполнительный орган власти, который реализует (исполняет) законы», «орган исполнительной власти» и т. д. Однако даже при подобном, казалось бы, формальном подходе граждане отмечали, что не понимают, чем занимаются члены правительства, а некоторые респонденты и вовсе давали достаточно критические оценки, отмечая, что решения принимаются властным институтом в пользу заинтересованных лиц, а не граждан: «люди, которые много зарабатывают, но непонятно чем занимаются», «принимает законы не для людей», «группа людей, которые стараются работать для себя и своих родственников и близких, а не для населения» и т. д. 
Удивительным является противоречие, заключающееся в том, что в настоящее время в нашей стране реализуется «Концепция открытости федеральных органов государственной власти», согласно которой приоритетной задачей для государства в области коммуникационной политики является применение комплексного подхода к увеличению открытости федеральных органов исполнительной власти. Однако результаты исследования демонстрируют, что коммуникационная политика Правительства РФ ведется не настолько эффективно, так как многие граждане нашей страны отмечают недостаточность информированности о деятельности высшего исполнительного органа власти в стране, отмечая, что в качестве идеального правительства видят честный, справедливый, открытый и готовый к диалогу политический институт.

Подводя итог, следует отметить, что в результате проведенного исследования автором были выявлены основные тенденции в восприятии образа Правительства РФ российскими гражданами:

1. Высокий эмоциональный уровень восприятия Правительства РФ с преобладанием негативных оценок деятельности данного органа власти, что отчасти объясняется проведением ряда непопулярных реформ (в частности, пенсионной реформы и повышения ставки НДС).

2. Снижение уровня доверия граждан к Правительству РФ в целом и Председателю Правительства РФ в частности. При этом следует отметить, что уровень доверия граждан к Председателю Правительства РФ ниже, чем уровень доверия к Правительству РФ в целом.

3. Восприятие Правительства РФ в качестве закрытой системы, оторванной от реальных проблем.

4. Недостаточная информированность граждан о деятельности Правительства РФ. Многие респонденты отмечали, что важным для органа исполнительной власти является «открытость деятельности и понятность гражданам принимаемых властных решений».

5. Противоречивые оценки деятельности Правительства РФ со стороны российских граждан, отражающие, с одной стороны, пассивность и слабость данного политического института, а с другой - его влиятельность и способность воздействовать на положение дел в стране.

\section{Обсуждение}

Текущая реальность социально-политического развития нашей страны требует коренных изменений к подходу взаимоотношений в системе «власть-общество». При анализе влияния политического контекста на восприятие Правительства РФ российскими гражданами следует отметить, что во внутренних коммуникациях присутствует некоторая отчужденность. Объяснить данную тенденцию можно стремлением власти к закрытости и отсутствием прямого диалога с населением. Многие респонденты отмечали, что видят в Правительстве РФ орган власти, способный изменить ситуацию в стране в лучшую сторону, но по какой-то причине не реализующий решения в пользу народа. Иллюстрации Правительства РФ как органа власти, закрытого и отчужденного от реальных проблем, как раз и подсвечивают имеющиеся противоречия во взаимодействии с гражданами и пробелы в коммуникационной политике.

Анализ и глубинное изучение политических образов позволяют выявить как особенности самого процесса восприятия, так и ключевые тенденции, принимая во 
внимание которые можно формировать новые представления и установки у граждан. Для зарождения и развития качественно нового процесса взаимодействия в системе «власть-общество» требуются доверие и позитивное восприятие друг другом власти и общества. А с помощью исследования восприятия политических институтов гражданами можно выделить их сильные и слабые стороны, что, в свою очередь, будет способствовать их эффективной деятельности в целом.

\section{Ссылки / References}

1. Жестков М. И. Политико-психологический анализ власти в современном политическом процессе Российской Федерации // Бизнес. Общество. Власть. 2011. № 7. С. 188-203.

2. ВЦИОМ. Деятельность государственных институтов: сайт [2019] // ВЦИOM. URL: https://wciom.ru/news/ratings/odobrenie_deyatelnosti_gosudarstvennyx_institutov (дата обращения: 25.02.2019).

3. Левада-Центр. Одобрение институтов власти: сайт. [2019] // Левада-Центр. URL: https://www.levada.ru/2019/07/05/odobrenie-institutov-vlasti-14 (дата обращения: 25.02.2019).

4. Пищева Т. Н. Политические образы: проблемы исследования и интерпретации // Полис. 2011. № 2. С. 47-52.

5. Леонтьев Д. А. От образа к имиджу. Психосемантический брендинг // Реклама и жизнь. М., 2000. № 1 (13). С. 19-22.

6. Шестопал Е. Б. Образ и имидж в политическом восприятии: актуальные проблемы исследования // Образы государств, наций, лидеров / Под ред. Е. Б. Шестопал. М.: Аспект Пресс, 2008. С. 8-24.

7. Путин 3.0: общество и власть в новейшей истории России / Под ред. Е. Б. Шестопал. М.: Аргамак-медиа, 2015. 420 с.

8. Власть и лидеры в восприятии российских граждан. Четверть века наблюдений (19932018): монография / Отв. ред. Е. Б. Шестопал. М.: Весь Мир, 2019. 656 с.

9. Палитай И. С. Методология политико-психологического исследования массового политического сознания в трансформирующихся обществах // Политическая наука. 2016. № Специальный выпуск. С. 193-203.

10. Селезнёва А. В. Образ Президента России В. В. Путина в сознании российских граждан // Русская политология - Russianpoliticalscience. 2018. № 7 (2). С. 4-11.

11. Смулькина Н. В. Факторы, влияющие на восприятие кандидатов в Президенты в российской избирательной кампании // Вестник Томского государственного университета. Философия, Социология. Политология. 2013. № 3. С. 30-36.

12. Джгамадзе К. Б., Рогозарь А. И. Влияние социально-демографических факторов на восприятие своей страны гражданами России // Вестник Московского государственного областного университета. 2017. № 2. С. 1-10.

13. Палитай И. С. Трансформация образов власти и политических лидеров Великобритании под влиянием Brexit (на материалах европейских и американских СМИ за 2014-2017 гг.) // Полис. Политические исследования. 2018. № 2. С. 150-162. 
14. Джгамадзе К. Б. Теоретико-методологические особенности изучения образа страны в массовом сознании // Вестник Кемеровского государственного университета. 2015. № 3. (63). Том 3. С. 40-44.

15. The measure and mismeasure of emotion / G. E. Marcus, M. MacKuen, J. Wolak, L. Keele // Feeling politics: Emotion in political information processing. NY.: Palgrave Macmillan, 2006. P. 31-45.

16. Шестопал Е. Б. Особенности использования психологических методов для изучения политического восприятия // Социальная психология и общество. 2018. Том 9. № 3. С. 81-90.

17. Особенности политического восприятия в современных российских условиях / А. Л. Зверев, И. С. Палитай, Н. В. Смулькина, А. И. Рогозарь // Полис. Политические исследования. 2016. № 3. С. 40-54.

18. ФОМ. О старых и новых министрах. Известность министров и оценка их компетентности: сайт [2018] // ФОМ. URL: https://fom.ru/Politika/14041 (дата обращения: 25.02.2019).

19. Левада-Центр. Более половины россиян выступают за отставку правительства: сайт [2019] // Левада-Центр. URL: https://www.levada.ru/2019/01/14/bolee-polovinyrossiyan-vystupayut-za-otstavku-pravitelstva/ (дата обращения: 25.02.2019). 